\title{
Comparative Analysis between Two Different Control PWM Techniques Based on
}

\section{a Reduced-Component Multilevel Inverter}

\author{
Cathrine E. S. Feloups ${ }^{1 \square}$, Essam E. M. Mohamed ${ }^{2}$
}

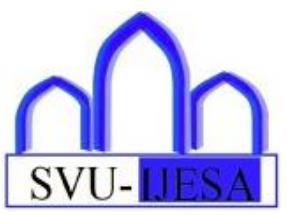

\begin{abstract}
This paper focuses on the implementation of two pulse width modulation (PWM) techniques on a reduced-component multilevel inverter which reduced the number of power switches along with the voltage sources used. The reduced components multilevel inverter has two circuits; level circuit and polarity circuit. The level circuit is used for producing voltage levels, whereas polarity is a conventional $\mathrm{H}$-bridge used for reversing output voltage levels. The reduction in harmonics is primarily dedicated by the switching technique used to control the power switches. In this paper, two PWM techniques were applied to the presented inverter to investigate the change in the switching signal period on ripple contents and total harmonic distortion (THD) with a closed-loop voltage control system. In the closed-loop system, a conventional PI controller is used to regulate the load voltage to achieve an output voltage near to sinusoidal. MATLAB/SIMULINK has been used to analyze the overall performance of the multilevel inverter based on seven-level operation under both PWM techniques. The simulation results show that the first PWM technique, which has a low switching time for the power switches, has an influence on the THD and the ripple content by about a 6 percent reduction compared with the second technique.
\end{abstract}

Keywords: PWM; Seven-level Inverter; Single phase; THD; Voltage Control.

\section{Introduction}

Received: 23 November 2020/ Accepted: 5 December 2020

$\square$ Corresponding Author:

${ }^{1}$ Cathrine E. S. Feloups, Cathrine.elia@eng.svu.edu.eg

${ }^{2}$ Essam E. M. Mohamed, Essam.mohamed@eng.svu.edu.eg

${ }^{1,2}$ Faculty of Engineering, South Valley University, Qena, 83523, Egypt.
Power electronics development has drawn much of the researcher's attention for its high performance and power capability [1]. This development has made it possible to create pulse width modulation (PWM) inverters that can control voltage and frequency. As a result, the use of power electronics has increased significantly in more industrial applications such as renewable energy systems [2], [3], uninterruptable power supplies (UPS) [4], flexible AC transmission systems (FACTS) [5], motor drives [6], etc., to improve the performance of these applications.

The three-level H-bridge PWM inverter circuit is the first circuit of dc-ac converter topologies [7]. As a result of the need for low total harmonic distortion (THD) and high efficiency, a demand for high voltage rating multilevel inverter (MLI) has grown. Another significant benefit for MLI is the absence of high-rated step-up transformers for high voltage applications.

The stepped output voltage from MLI presents a voltage shape very similar to the sinusoidal waveform; consequently, THD, dv/dt stress, and output filter size are reduced [8]. Mainly, the three most popular MLI topologies are diode-clamped MLI, flying capacitor MLI, and cascaded H-bridge MLI [8]-[10]. All these common topologies suffer from a high number of switching devices and result in high switching losses, low efficiency, and high overall topology costs for higher rated applications.

The most challenging issue is how to achieve low THD output voltage, low filter circuit, low cost and high efficiency. In this case, a reduction in the number of switching devices components is considered to be the solution to this problem. Recently, several topologies have been recommended as a replacement for the familiar topologies of MLI. Each topology has shown its effective solution to one or more of the aforementioned problems related to the common traditional MLI topologies.

The key element for the use of MLI is the harmonic content which is determined by the proper switching for each switch forming the topology used. This paper 
introduces two PWM techniques based on different control and generation of different voltage levels in order to demonstrate how this affects them.

This paper is structured as follows: Section 2 addresses the construction of a reduced-component multilevel inverter used in the study of the two PWM techniques and the operation of seven-level topology. The switching scheme of the two PWM techniques is demonstrated in Sections 3. The voltage regulation scheme is set out in Section 4. Section 5 discloses the validity of the proposed inverter using MATLAB/SIMULINK. This work is concluded in Section 6.

\section{A Reduced-Component Multilevel Inverter}

\subsection{Circuit Configuration}

The illustration of a reduced-component multilevel inverter is shown in Fig. 1 as set out in [11], [12]. It has two circuits; the level circuit and the polarity circuit. The level circuit comprises of " $n$ " cells with each cell, from the $2^{\text {nd }}$ to $\mathrm{n}^{\text {th }}$ cells, having one voltage source and one IGBT switch without an antiparallel diode, but, the $1^{\text {st }}$ cell has one source and one switch along with its antiparallel diode is used for the output of the first level, in contrast, the IGBT switch is used for the freewheeling path in case of inductive loads. This circuit is responsible for producing various voltage levels for the inverter terminal. On the other hand, the polarity circuit is called a traditional three-level H-bridge circuit whose key functions are to control the polarity of the voltage levels and to produce the zero voltage level.

\subsection{Operational Principle of Seven-level}

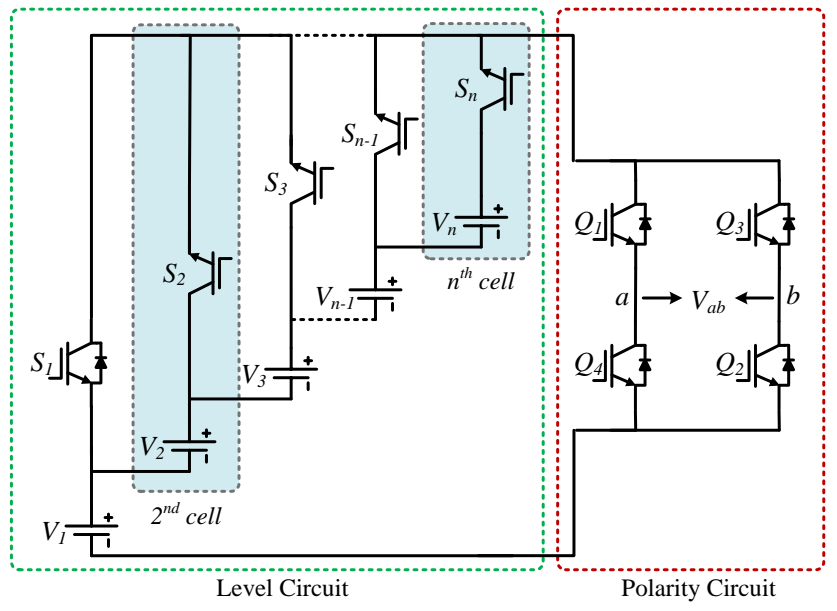

Fig. 1 Circuit configuration of the reduced-component inverter
For seven-level topology, the inverter has three cells including three symmetrical voltage sources i.e., $V_{I}=V_{2}=$ $V_{3}=V_{d c}$ and seven IGBT switches that control output voltage levels. The seven output levels are $+V_{d c},+2 V_{d c}$, $+3 V_{d c}, 0,-V_{d c},-2 V_{d c}$, and $-3 V_{d c}$. The output voltage from the inverter has nine states depending on the switches in the ON state as listed in Table 1. Besides, to understand the turning $\mathrm{ON}$ and $\mathrm{OFF}$ of each switch, Fig. 2 summarizes the current direction of the seven-level generation.

Table 1 Switching combination of seven-level inverter

\begin{tabular}{cccc}
\hline State & $\begin{array}{c}\text { Inverter output } \\
\text { voltage }\left(V_{a b}\right)\end{array}$ & $\begin{array}{c}\text { Direction of load } \\
\text { output current }\left(I_{o u t}\right)\end{array}$ & $\begin{array}{c}\text { Switches in ON } \\
\text { state }\end{array}$ \\
\hline a. & $3 V_{d c}$ & Positive & $S_{3}, Q_{1}, Q_{2}$ \\
b. & $2 V_{d c}$ & Positive & $S_{2}, Q_{1}, Q_{2}$ \\
c. & $V_{d c}$ & Positive & $D_{S l}, Q_{1}, Q_{2}$ \\
d. & $V_{d c}$ & Negative & $S_{1}, D_{Q 1}, D_{Q 2}$ \\
e. & 0 & Positive & $Q_{1}, D_{Q 3}$ \\
f. & $-V_{d c}$ & Negative & $D_{S l}, Q_{3}, Q_{4}$ \\
g. & $-V_{d c}$ & Positive & $S_{1}, D_{Q 3}, D_{Q 4}$ \\
h. & $-2 V_{d c}$ & Negative & $S_{2}, Q_{3}, Q_{4}$ \\
i. & $-3 V_{d c}$ & Negative & $S_{3}, Q_{3}, Q_{4}$ \\
\hline
\end{tabular}

\section{Switching PWM Algorithm}

The ON and OFF modes of each switch and the switching frequency $\left(F_{S W}\right)$ are the key contributors to harmonic content of the produced output voltage. In the following subsections, two PWM techniques will be shown to present the effect of the switching method on THD. The switching pattern used to produce a seven-level output voltage is created by comparing a rectified sinusoidal reference signal $\left(V_{r e f}\right)$ has a frequency of the required output voltage with triangle carrier signals. The numbers of carrier $\left(N_{c a r}\right)$ are determined by the following equation:

$N_{c a r}=\left(N_{l}-1\right) / 2$

Where; $N_{l}$ is the number of voltage levels required. In this case, for seven-level voltage, three carrier signals are needed for each PWM Technique.

\subsection{PWM Tech-I}

The first PWM technique would have three carrier signals (i.e. $V_{c a r 1}, V_{c a r 2}$, and $V_{c a r 3}$ ). All of these carriers have the same $F_{S W}$ value, the same peak value but different in offset voltage as indicated in Fig. 3. The intersection points between $V_{c a r l}, V_{c a r 2}$, and $V_{c a r 3}$ with a $V_{\text {ref }}$ decide the output voltage levels. 


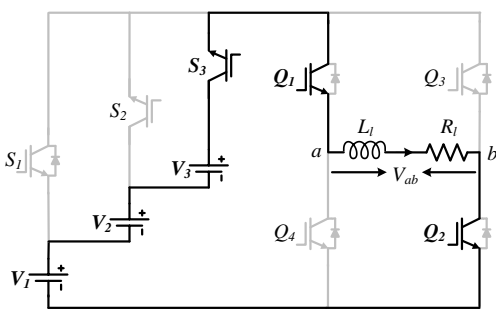

(a)

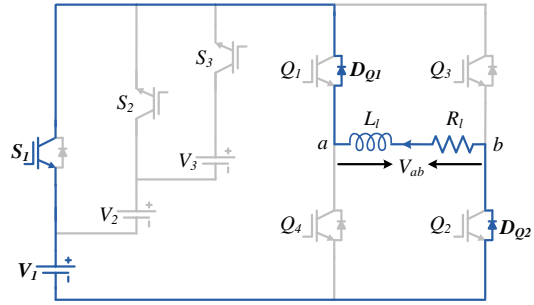

(d)

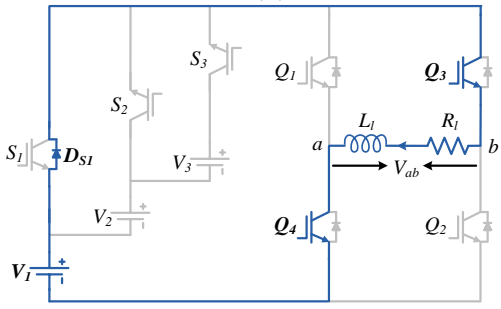

(g)

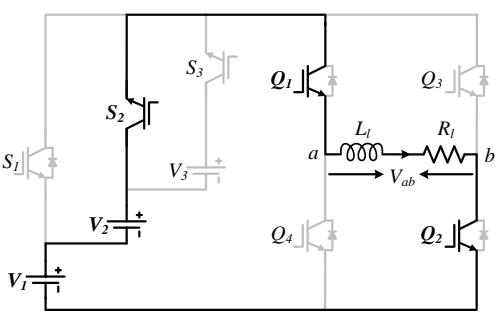

(b)

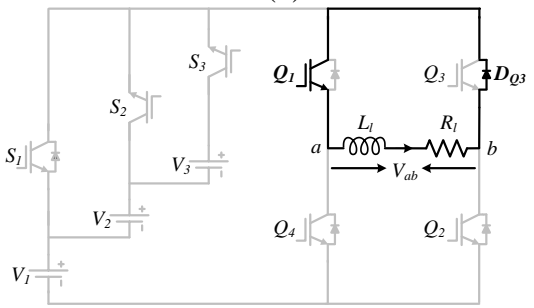

(e)

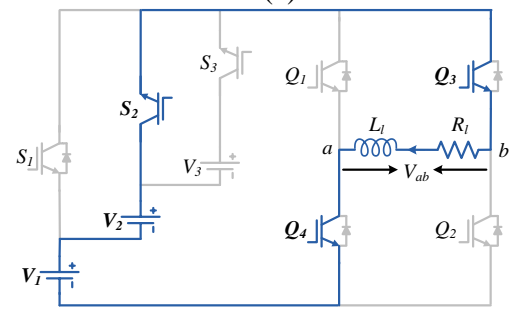

(h)

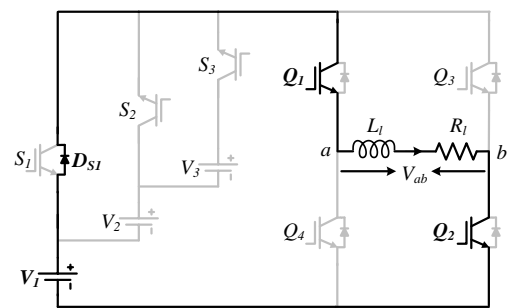

(c)

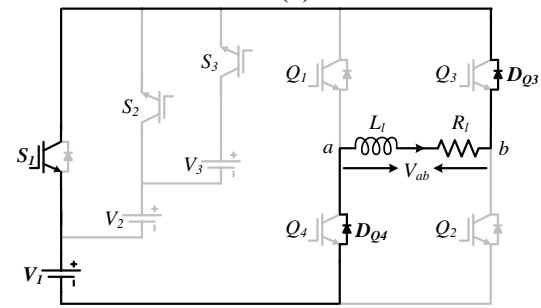

(f)

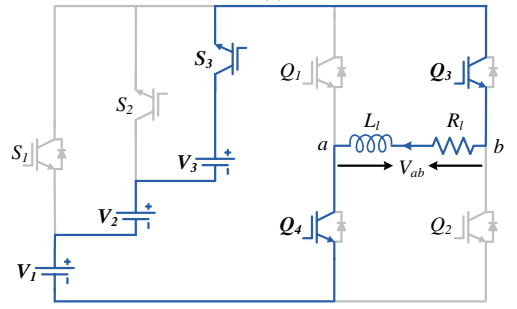

(i)

Fig. 2 Current path for generating the seven levels.

The modulation index $(M I)$, which will present the number of levels at the terminals of the inverter, can be calculated as follow:

$M I=A_{m} /\left(3 * A_{c}\right)$

Where, $A_{m}$ is the amplitude of $V_{\text {ref }}$ and $A_{c}$ is the peak-to-peak value of a carrier signal.

When $V_{\text {ref }}$ intersects $V_{\text {carl }}$, the $C_{A}$ control signal is produced and the first output voltage levels, $\pm V_{d c}$, are generated. The second levels, $\pm 2 V_{d c}$, of the output voltage are created by intersecting $V_{\text {ref }}$ with $V_{c a r 2}$. Also, the $C_{B}$ control signal is produced. The last output voltages, $\pm 3 \mathrm{~V}_{\mathrm{dc}}$, are generated when the intersection between $V_{\text {ref }}$ and $V_{\text {car } 3}$ occurs and the $C_{C}$ control signal is generated. The gating signal for each IGBT switch is produced by the proper switching combination. The positive half-cycle of $V_{\text {ref }}$ is responsible for generating positive levels while the rectified half-cycle of $V_{\text {ref }}$ is responsible for generating the negative levels.

In one cycle, the H-bridge lower leg switches $\left(Q_{2}\right.$ and $\left.Q_{4}\right)$ are switched at fundamental frequency, while the H-bridge upper leg switches $\left(Q_{1}\right.$ and $\left.Q_{3}\right), S_{1}, S_{2}$ and $S_{3}$ are switched at the $F_{S W}$.

\subsection{PWM Tech-II}

In this PWM technique, the three carriers have the same $F_{S W}$, but the peak with no voltage offset is calculated by the following equation:

$\operatorname{Car}_{p}=\operatorname{Car}_{n} / 2$

Where; $\operatorname{Car}_{p}$ is the carrier's peak value and $\mathrm{Car}_{n}$ is the carrier's number. In this case, $V_{\text {carl }}$ is the first carrier $\left(\mathrm{Car}_{n}=1\right)$ and the peak value based on Eq. 2 equals to 0.5, $V_{\text {car } 2}$ is the second carrier $\left(\mathrm{Car}_{n}=2\right)$ and has a peak value equal to 1.0, and finally $V_{c a r 3}$, the third carrier $\left(\mathrm{Car}_{n}=3\right)$, has a peak value of 1.5, as shown in Fig. 4. MI here is calculated as following:

$M I=\left(2 * A_{m}\right) / 3$

The generation of each level is the same as that of PWM Tech-I by intersecting $V_{c a r l}, V_{c a r 2}$, and $V_{c a r 3}$ with $V_{\text {ref }}$ in the same way, and the gating signal for the switches is obtained by an appropriate switching combination.

\section{Voltage Control Scheme}

The voltage control scheme is a closed-loop voltage regulation for the output voltage. It consists of two parts; the power and control circuit as shown in Fig. 5. The 


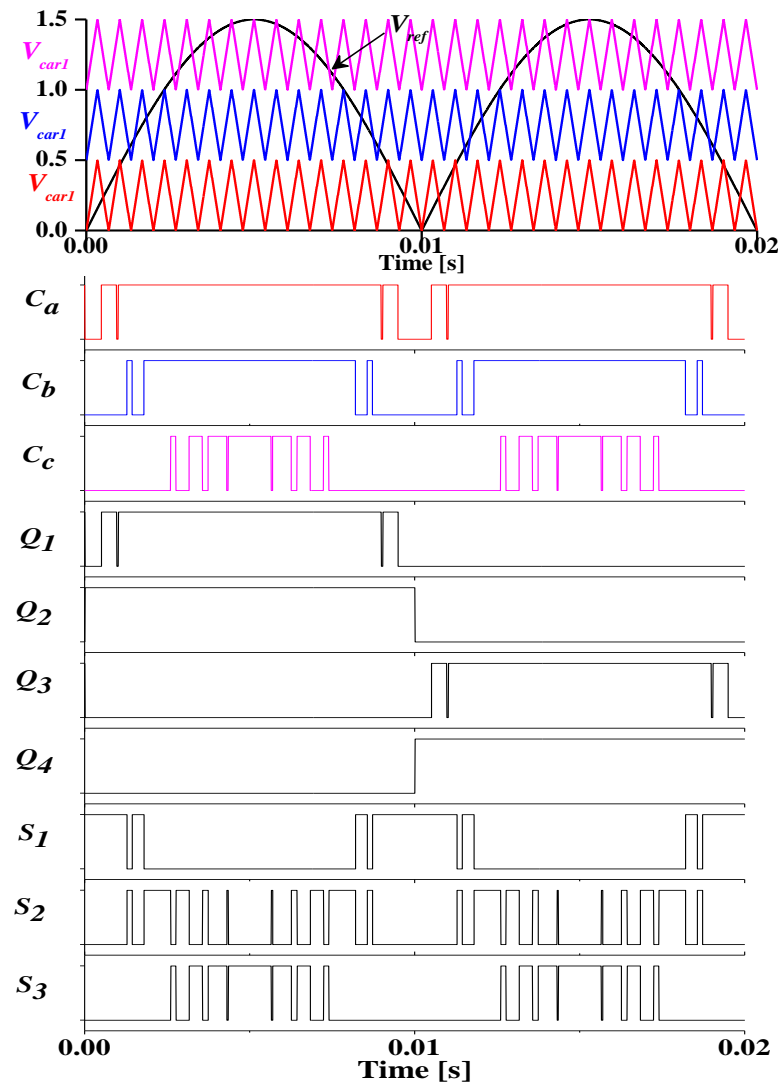

Fig. 3 Switching pattern of PWM Tech-I.

circuit is the seven-level inverter with a simple filter and resistive load, while the control circuit is mainly based on a feedback system using a PI controller. The LC filter is based on the reduction of the ripple found in both the output voltage and the inverter current.

The main function of the PI controller is to control the load voltage $\left(V_{L}\right)$ to be as sinusoidal as the reference voltage $\left(V_{R}\right)$. Therefore an error signal is created by comparing the load voltage with the reference voltage. The error is applied to the PI controller that generates the modulated signal $(\mathrm{U})$ and that signal is applied to one of the two PWM techniques as a reference signal to show the switching states required to generate the inverter levels.

\section{Simulation Results}

The MATLAB/SIMULINK is designed to present the validity of the reduced-component multilevel inverter during operation with two separate PWM control techniques when connected to the resistive load. The parameters used in the Simulink are listed in Table 2. The results are shown in different $M I$ values for generating different voltage levels. The inverter output voltage can be
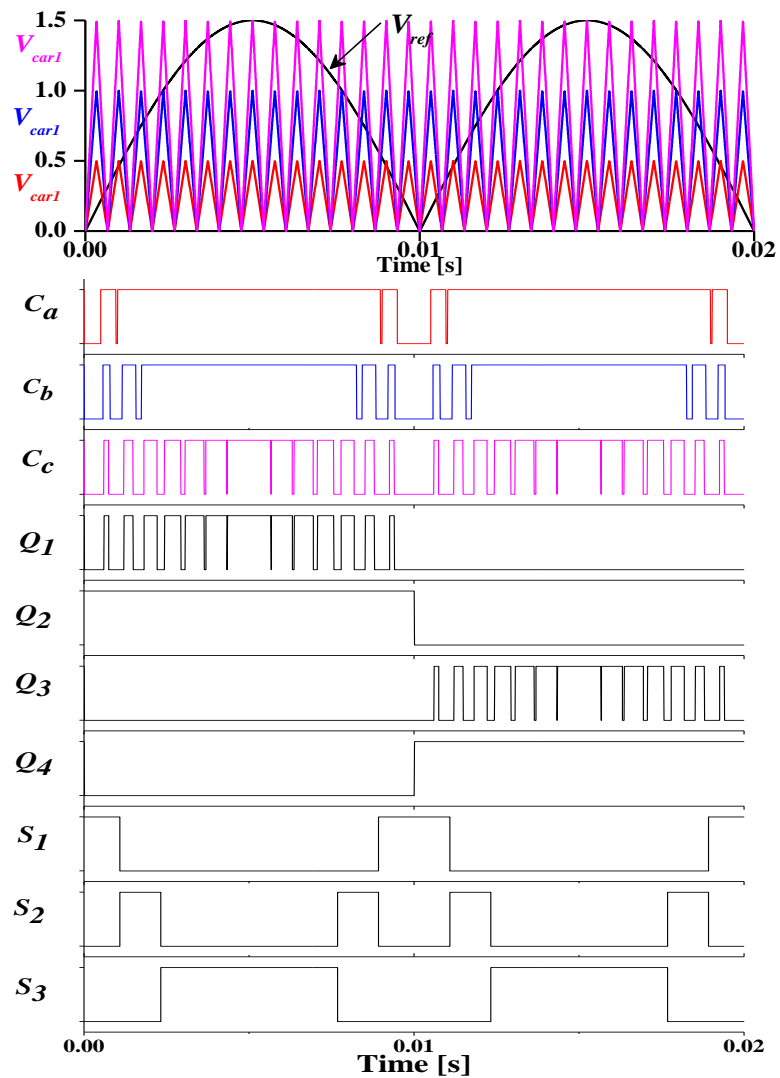

Fig. 4 Switching pattern of PWM Tech-II.

three, five or seven levels, depending on the MI. The different $M I$ values demonstrate the effectiveness of each PWM technique in controlling the load voltage with respect to the reference value. There are three levels at $M I$ below 0.33 . $M I$ is set from 0.33 to 0.67 for five levels. Seven levels are synthesized to $M I$ greater than 0.67 . The $V_{R}$ peak used for the closed-loop feedback system is set to $10 \mathrm{~V}, 40 \mathrm{~V}$ and $70 \mathrm{~V}$ in order to obtain different $M I$ values (i.e. $0.11,0.44$, and 0.77).

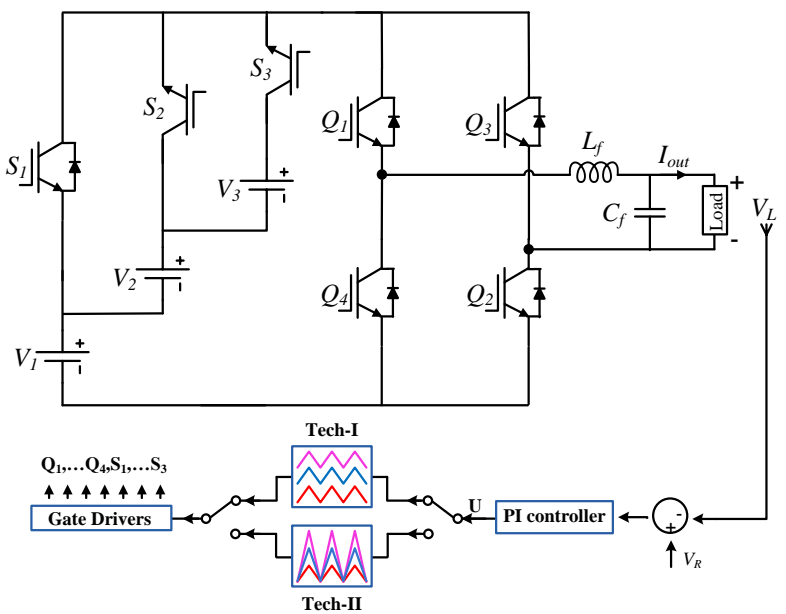

Fig. 5 The closed-loop voltage control scheme. 
Table 2 Simulation Parameters

\begin{tabular}{lccc}
\hline Specification & Symbol & Value & Unit \\
\hline DC power supplies & $V_{I}=V_{2}=V_{3}$ & 30 & $\mathrm{~V}$ \\
Switching frequency & $F_{S W}$ & 10 & $\mathrm{kHz}$ \\
Fundamental frequency & $F_{f}$ & 50 & $\mathrm{~Hz}$ \\
Sampling time & $T_{s}$ & 5 & $\mu \mathrm{s}$ \\
Filter & $L_{f}$ & 1 & $\mathrm{mH}$ \\
& $C_{f}$ & 3 & $\mu \mathrm{F}$ \\
Load & $R_{l}$ & 42 & $\Omega$ \\
\multirow{2}{*}{ PI controller gains } & $K_{p}$ & 0.005 & $\mathrm{~A} / \mathrm{V}$ \\
& $K_{i}$ & 10000 & $\mathrm{~A} / \mathrm{V} . \mathrm{S}$ \\
\hline
\end{tabular}

\subsection{Simulation Results Using PWM Tech-I}

The simulation results for the closed-loop voltage control system for a seven-level inverter with resistive load under PWM Tech-I are shown in Fig. 6, Fig. 7, and Fig. 8.

Fig. 6 presents the results at $M I<0.33$. The inverter output voltage consists of three levels in the terminal as shown in Fig. 6(a). In Fig. 6(b), reference and load output voltages $\left(V_{R}, V_{L}\right)$ are presented. As can be seen, the output voltage effectively tracks the reference voltage. Finally, Fig. 6(c) shows the current of the load which is in phase with the load output voltage. Fig. 7 demonstrates the results for $M I$ between 0.33 and 0.67 . As can be seen in Fig. 7(a), the inverter terminal compromise five levels in addition, $V_{R}$ and $V_{L}$ appear identical in Fig. 7(b). Similarity Fig. 8(a) presents seven levels at the terminals of the inverter at MI greater than 0.67. In the same way, Fig. 8(b) and (c) show the reference and load voltages and the load current, respectively.

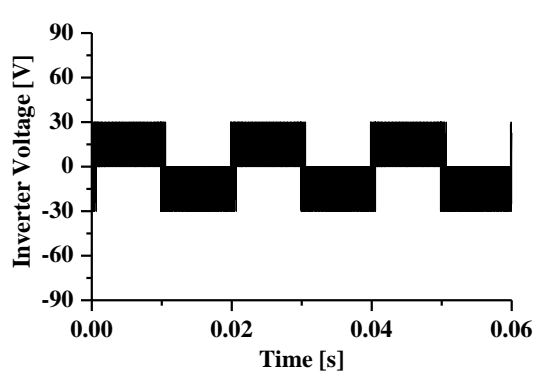

(a)

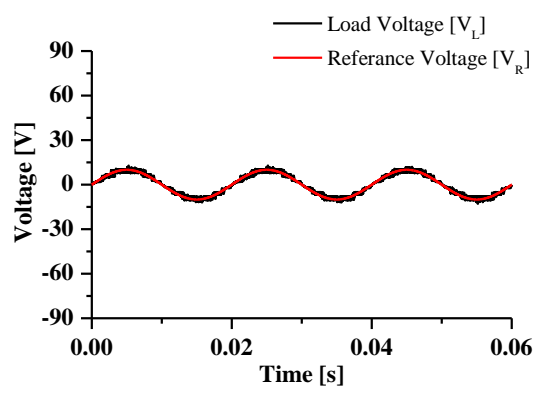

(b)

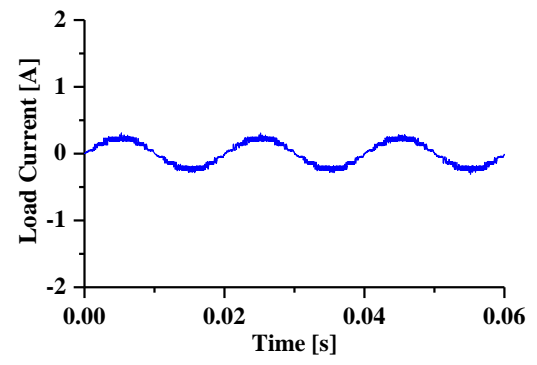

(c)

Fig. 6 Simulation results of the single-phase seven-level inverter using PWM Tech-I at $M I=0.11$.

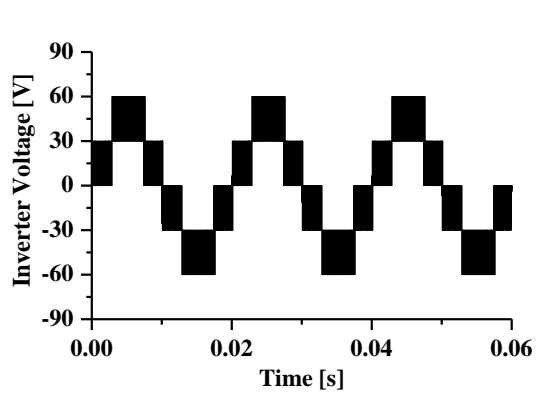

(a)

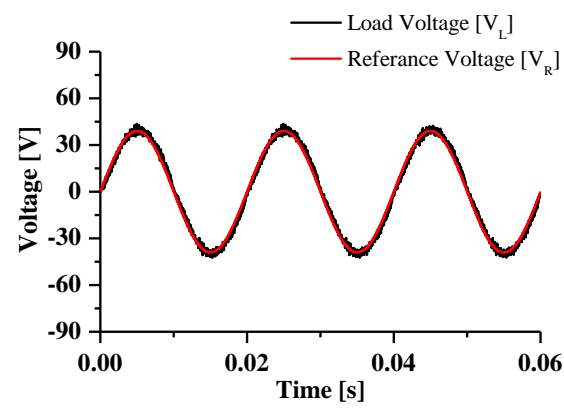

(b)

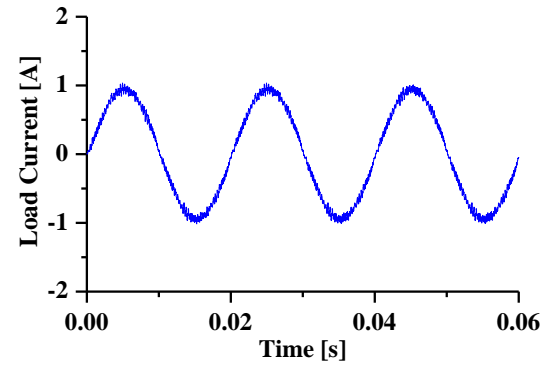

(c)

Fig. 7 Simulation results of the single-phase seven-level inverter using PWM Tech-I at $M I=0.44$.

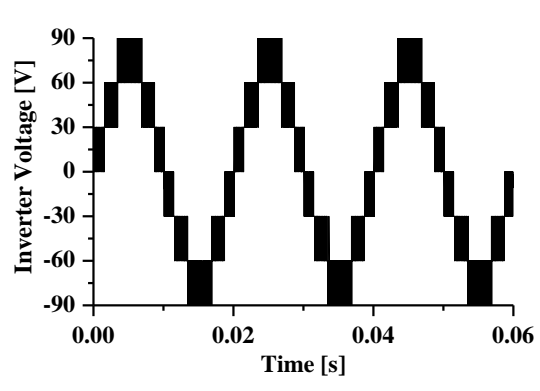

(a)

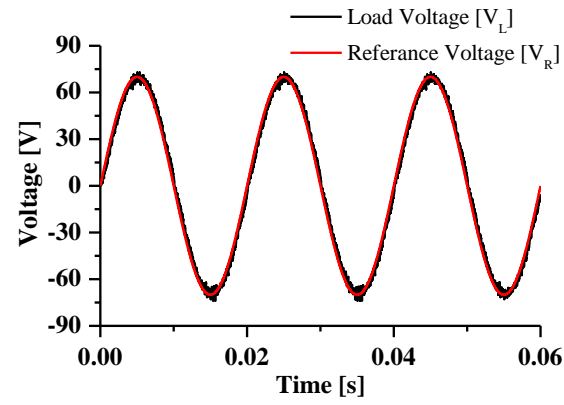

(b)

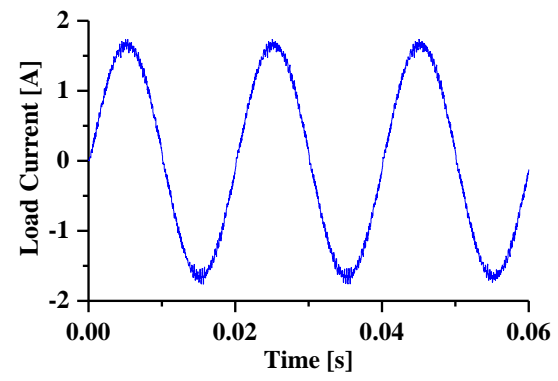

(c)

Fig. 8 Simulation results of the single-phase seven-level inverter using PWM Tech-I at $M I=0.77$. 


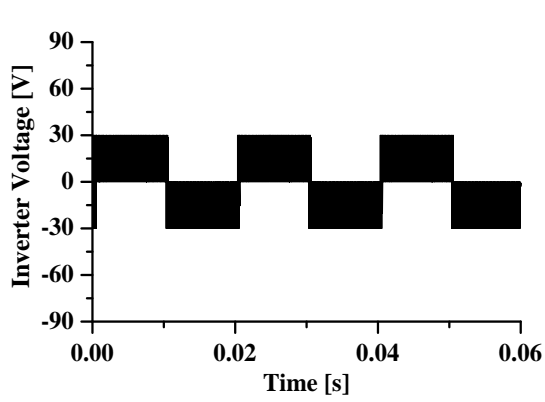

(a)

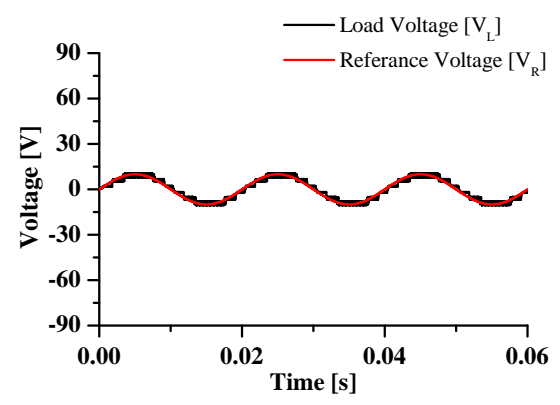

(b)

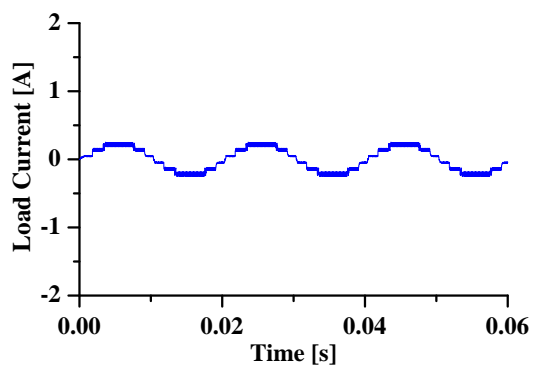

(c)

Fig. 9 Simulation results of the single-phase seven-level inverter using PWM Tech-II at $M I=0.11$.

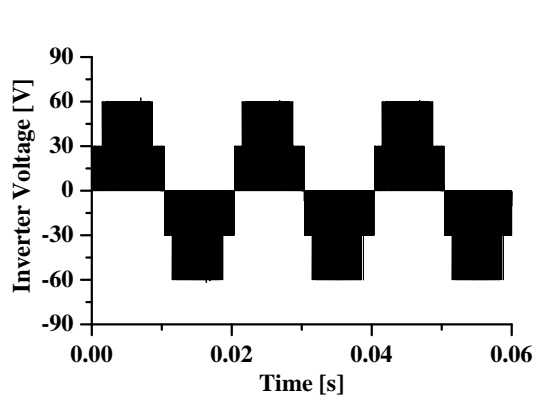

(a)

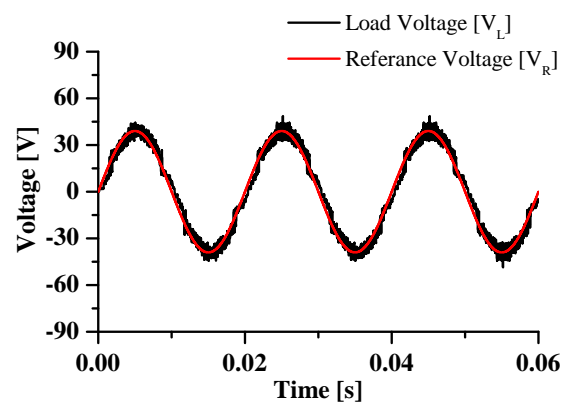

(b)

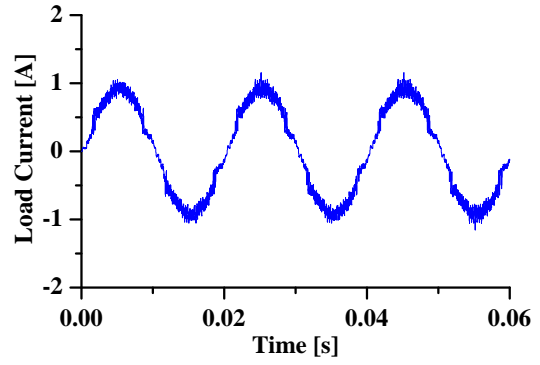

(c)

Fig. 10 Simulation results of the single-phase seven-level inverter using PWM Tech-II at $M I=0.44$.

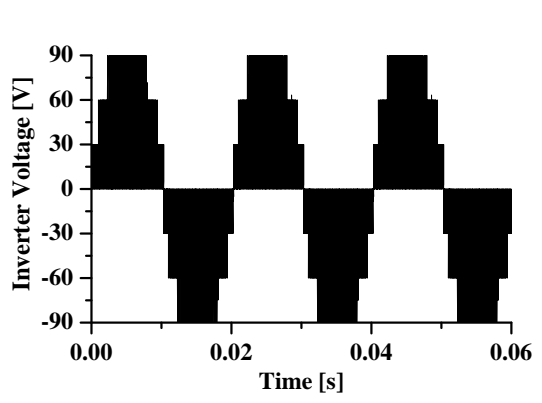

(a)

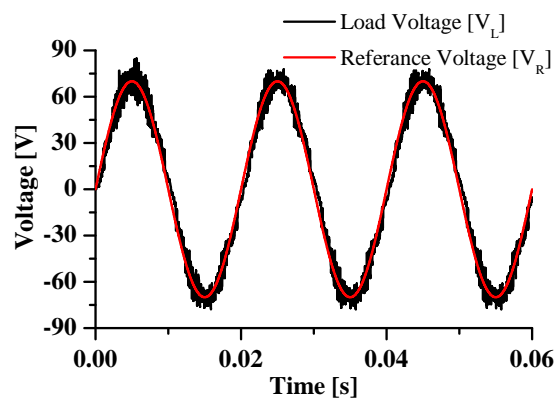

(b)

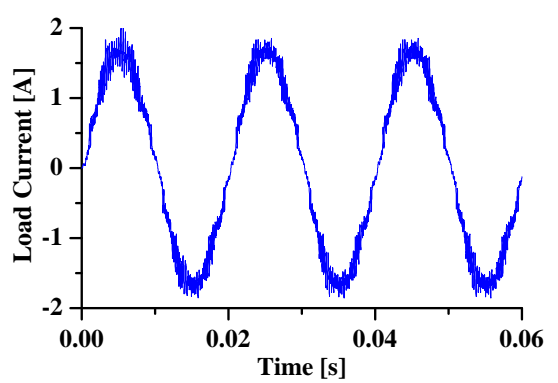

(c)

Fig. 11 Simulation results of the single-phase seven-level inverter using PWM Tech-II at $M I=0.77$.

\subsection{Simulation Results Using PWM Tech-II}

Fig. 9, 10, and 11 display seven-level inverter simulation results using PWM Tech-II. Same as PWM Tech-I, Fig. 9(a) presents three levels at the inverter terminal as $M I$ is less than 0.33 . Fig. 9(b) presents the voltages for load and reference that are nearly identical. Load current is shown in Fig. 9(c). For $0.33<M I<0.67$, Fig. 10 presents the results of simulation to obtain five levels from the inverter. Fig. 10(a) shows the five levels while, Fig. 10(b) displays the load and reference voltages, and finally Fig. 10(c) presents the load current. Fig. 11(a) introduces the inverter's seven-level output voltage before filtering. As can be shown in both techniques, the waveform is not the same due to the change in generating the voltage levels. Fig. 11(b) displays the system reference results and the actual load voltages. The reference and the actual load voltages are almost identical. The waveform of the load current is shown in Fig. 11(c).

However, the ripples in the sinusoidal waveforms of the load voltages and currents are increased due to the rise in the switching time of each power switch. This condition in turn raises the harmonics in both voltages before and after use of the filter.

In order to present the effectiveness of each PWM technique, THD has been determined for both techniques before and after the filter at different $M I$ values and the results are shown in Table 3. At MI less than 0.33 , both techniques present almost the same THD for voltages as the switching period for power switches 
under the PWM techniques is the same. However, the inverter exhibits better characteristics under PWM Tech-I compared to PWM Tech-II with low THD in both inverter and load voltage from the deep aforementioned comparisons at $M I$ greater than 0.33 . The reason for this is that the number of levels has increased and the switching period of the power switches has also changed.

Table 3 Total harmonic distortion for the inverter and output voltages at different values of MI for both PWM techniques

\begin{tabular}{cccc}
\hline & & $\begin{array}{c}\text { PWM } \\
\text { Tech-I }\end{array}$ & $\begin{array}{c}\text { PWM } \\
\text { Tech-II }\end{array}$ \\
\hline THD of the inverter & $\mathrm{MI}<0.33$ & $84.5 \%$ & $84.06 \%$ \\
voltage (before & $0.33<\mathrm{MI}<0.67$ & $39.41 \%$ & $67.32 \%$ \\
filtering) & $\mathrm{MI}>0.67$ & $24.13 \%$ & $55.68 \%$ \\
\hline THD of the load & $\mathrm{MI}<0.33$ & $14.06 \%$ & $15.65 \%$ \\
voltage (after & $0.33<\mathrm{MI}<0.67$ & $5.29 \%$ & $10.99 \%$ \\
filtering) & $\mathrm{MI}>0.67$ & $3.39 \%$ & $9.85 \%$ \\
\hline
\end{tabular}

\section{Conclusions}

In this paper, the performance of two PWM techniques is presented to generate a seven-level voltage using a reduced-component multi-level inverter topology. In all of the two PWM techniques, each technique depends on the duration of the switching signal for each power switch that contributes to the inverter topology used. The effectiveness of each PWM technique is theoretically checked by using MATLAB as a Simulink tool closed-loop system for stand-alone operation. It is clear that the gating method of each switch is the main element for low THD generation. The results show that PWM Tech-I can produce a low THD for the output voltage before and after filtering as the switching period of each power switch is lower than that of PWM Tech-2.

\section{References}

[1] J. C. Balda and A. Mantooth, "Power-Semiconductor Devices and Components for New Power Converter Developments: A key enabler for ultrahigh efficiency power electronics," IEEE Power Electron. Mag., vol. 3, no. 2, pp. 53-56, 2016.

[2] A. I. M. Ali, M. A. Sayed, and E. E. M. Mohamed, "Modified efficient perturb and observe maximum power point tracking technique for grid-tied PV system," Int. J. Electr. Power Energy Syst., vol. 99, no. July, pp. 192-202, 2018, doi: 10.1016/j.ijepes.2017.12.029.

[3] C. E. S. Feloups, A. I. M. Ali, and E. E. M. Mohamed, "Single-phase seven-level PWM inverter for PV systems employing multi-level boost converter," Proceedings of 2018 International Conference on Innovative Trends in Computer Engineering, ITCE 2018, vol. 2018-March. pp. 403-409, 2018, doi: 10.1109/ITCE.2018.8316658.

[4] W. R. N. Santos, E. de Moura Fernandes, E. R. C. da Silva, C. B. Jacobina, A. C. Oliveira, and P. M. Santos, "Transformerless single-phase universal active filter with UPS features and reduced number of electronic power switches," IEEE Trans. Power Electron., vol. 31, no. 6, pp. 4111-4120, 2015.

[5] D. Baimel, "Implementation of DQ0 control methods in high power electronics devices for renewable energy sources, energy storage and FACTS," Sustain. Energy, Grids Networks, vol. 18, p. 100218, 2019.

[6] C. E. S. Feloups and E. E. M. Mohamed, "Current Control Strategies for Two-Phase Induction Motor Driven by Three-Leg Voltage Source Inverter," in 2018 Twentieth International Middle East Power Systems Conference (MEPCON), 2018, pp. 679-684.

[7] F. Wang, "Sine-triangle versus space-vector modulation for three-level PWM voltage-source inverters," IEEE Trans. Ind. Appl., vol. 38, no. 2, pp. 500-506, 2002.

[8] G. P. Adam, S. J. Finney, A. M. Massoud, and B. W. Williams, "Capacitor balance issues of the diode-clamped multilevel inverter operated in a quasi two-state mode," IEEE Trans. Ind. Electron., vol. 55, no. 8, pp. 3088-3099, 2008, doi: 10.1109/TIE.2008.922607.

[9] D. W. Kang, B. K. Lee, J. H. Jeon, T. J. Kim, and D. S. Hyun, "A symmetric carrier technique of CRPWM for voltage balance method of flying-capacitor multilevel inverter," IEEE Trans. Ind. Electron., vol. 52, no. 3, pp. 879-888, 2005, doi: 10.1109/TIE.2005.847574.

[10] A. S. M. Antony, "Cascaded multilevel inverter of 11 levels for RL load with reduced distortion," Indian J. Sci. Technol., vol. 8 , no. 19, pp. 10-12, 2015, doi: 10.17485/ijst/2015/v8i19/61692.

[11] C. E. S. Feloups and E. E. M. Mohamed, "A Novel Reduced Components Model Predictive Controlled Multilevel Inverter for Grid-Tied Applications," Adv. Electr. Electron. Eng., vol. 17, no. 3, pp. 251-261, 2019.

[12] C. E. S. Feloups and E. E. M. Mohamed, "Design and Implementation of a New Multilevel Inverter Employing Reduced Components," Open Access Libr. J., vol. 6, no. 9, pp. $1-17,2019$. 